\title{
O ACOLHIMENTO SOB A ÓTICA DOS USUÁRIOS DE SUBSTÂNCIAS PSICOATIVAS QUE FREQUENTAM O CAPS AD DO MUNICÍPIO DE FEIRA DE SANTANA

\author{
Everthon Fraga de Oliveira ${ }^{1}$ Carina Pimentel Souza Batista ${ }^{2}$; Sinara Lima de \\ Souza $^{3}$ e Camila Cerqueira Rios ${ }^{4}$
}

\author{
1. Voluntário PVIC, Graduando em Enfermagem, Universidade Estadual de Feira de Santana, e-mail: \\ everthonfraga@hotmail.com \\ 2. Orientador, Departamento de Saúde, Universidade Estadual de Feira de Santana, e-mail: \\ carinapimentel@hotmail.com \\ 3. Participante do projeto Percepção do acolhimento pelos usuários de um CAPS ad do interior da Bahia, Departamento de \\ Saúde, Universidade Estadual de Feira de Santana, e-mail: \\ sinarals@uefs.br \\ 4. Participante do projeto Percepção do acolhimento pelos usuários de um CAPS ad do interior da Bahia, Departamento de \\ Saúde, Universidade Estadual de Feira de Santana, e-mail: \\ mila.c.r@hotmmail.com
}

PALAVRAS-CHAVE: Saúde Mental; acolhimento; drogas ilícitas.

\section{INTRODUÇÃO}

Com o advento da Reforma Psiquiátrica o indivíduo com transtorno mental passou a ser visto como detentor de direitos e segundo Tanaka e outros (2009) novas práticas em saúde mental surgiram, como os Centros de Atenção Psicossocial (CAPS). Os CAPS são centrados nas necessidades dos usuários, possibilitando a integração familiar e social, a assistência psicossocial e a reabilitação do indivíduo (BRASIL, 2015). Pode ser estruturado em dimensões conforme a demanda e o perfil dos usuários, tais como, CAPS I e CAPS II; CAPSi; CAPS ad. Esse serviço propõe acolhimento, escuta e vínculo, além da proposta do projeto terapêutico singular (BRASIL, 2004). Para Jorge e outros (2011) o acolhimento possibilita o cuidado integral, sendo um alavanque na saúde, através do vínculo estabelecido entre os usuários do serviço, profissionais e gestores que visam à humanização dessa assistência.

O uso de substâncias psicoativas e a sua dependência trata-se de uma questão de saúde pública (ALVAREZ ET AL, 2012), uma vez que afeta as relações familiares e sociais. Nesta perspectiva, o acolhimento orienta as práticas em saúde e aproxima o indivíduo a rede de atenção psicossocial. Assim, é de grande relevância o estudo sobre o acolhimento desses usuários sob a ótica dos profissionais do CAPS ad, por conta também do preconceito e da associação com a periculosidade e criminalidade que pode comprometer o processo de acolhimento desses usuários, bem como, a assistência prestada pelos profissionais.

\section{METODOLOGIA}

Trata-se de uma pesquisa qualitativa, exploratória e descritiva, pois buscou-se uma abordagem do fenômeno pelo levantamento de informações que levaram o pesquisador a conhecer mais a seu respeito (TRIVIÑOS, 2008; GIL, 2010). A coleta de dados foi realizada no Centro de Atenção Psicossocial para usuários de álcool e outras drogas (CAPS ad) do município de Feira de Santana-Ba. Participou do estudo, usuários do Grupo Ajuda Mútua Droga, destinado a indivíduos que fazem uso de substâncias psicoativas. Como critério de inclusão tivemos: usuários que estavam devidamente vinculados ao grupo; que frequentavam regularmente; maiores de 18 anos; que não estivessem sob o efeito do uso de substâncias psicoativas no momento da coleta; que estivessem em condições mentais devidas sem torpor, fuga de ideias e confusão mental. Os critérios de exclusão foram estabelecidos para aqueles que não estavam aptos aos critérios de inclusão. A técnica de coleta de dados foi o Grupo Focal que consiste numa entrevista realizada em grupo que possibilita a discussão de pontos de vista e processos emocionais, a partir de uma determinada temática (GATTI, 2005). Caracteriza-se por ser uma técnica de pesquisa qualitativa que a partir de uma temática abordada, busca promover uma discussão entre os participantes sendo capaz de gerar através da interação social maior 
diversidade e riqueza nas respostas (GASKELL, 2002 apud LEITE ET AL, 2010). Os aspectos éticos foram adotados segundo a Resolução 466/2012 que regulamenta pesquisas envolvendo seres humanos (BRASIL, 2012). Trata-se de um recorte da pesquisa Percepção do acolhimento pelos usuários de um CAPS ad do interior da Bahia, aprovada no Comitê de Ética em Pesquisa (CEP - UEFS) com CAAE: 31689414.3.0000.0053 e com Resolução CONSEPE nº 090/2015.

\section{RESULTADOS E/OU DISCUSSÃO}

Os resultados obtidos foram através do grupo Ajuda Mútua Droga, denominado grupo D, que funciona desde 2005, quando também o CAPS ad foi implantado no município. O grupo é formado por homens com faixa etária de 26 a 49 anos, tendo em média 20 a 30 participantes por grupo. O presente estudo possibilitou trabalhar com três categorias de análise, por meio do grupo focal, tais como, a percepção de acolhimento; a satisfação com o atendimento e melhoria no atendimento:

\section{A percepção de acolhimento}

Propor intervenção a dependentes químicos exige dos profissionais preparo quanto ao recebimento e acolhimento desses indivíduos. Significa estar sensível com o sofrimento, livre de qualquer julgamento, preconceito, utilizar a escuta qualificada, considerando as subjetividades. Esse aspecto é perceptível na fala dos usuários:

''É bom, é a segunda vez que eu tô aqui, as pessoas me tratam bem, me tratam com amor, com carinho.",

' $E$ eu só tenho a dizer, desde o início do meu tratamento eu fui bem acolhido por todas as pessoas, desde da, da pessoa que faz a faxina até as assistentes sociais, as enfermeiras, todas as pessoas aqui me tratam super bem, e eu só tenho coisas boas a dizer delas."

É evidente nas falas dos usuários a percepção do acolhimento, reconhecendo a proposta do CAPS que é fundamentada na produção de vínculo que facilita essa adesão. Segundo Jorge e colaboradores (2011), o vínculo entre usuários e profissionais acontece mediante a constituição dos laços afetivos entre esses sujeitos, no que concerne ao atendimento de qualidade, o respeito, a confiança e a resolubilidade dos problemas.

Nesta perspectiva de relação do acolhimento com o respeito e a confiança, os usuários reiteram tal concepção aliada a ausência do estigma pelos profissionais da instituição, na compreensão de que o acolhimento no CAPS não tem restrição. Conforme os relatos abaixo:

'Aqui tem os profissionais (...) com bastante educação, que não tem preconceito com a gente, trata a gente de igual pra igual, mesmo a gente sendo dependente químico (...).

"Aqui eu me sinto bem, aqui ninguém nunca me falou nada de ruim não."

Segundo Bard e outros (2016) esses tipos de estereótipos implicam em sentimentos ruins, quando esses indivíduos são diminuídos, excluídos, estigmatizados e negligenciados na sociedade por consumirem drogas ilícitas. Romanini e Roso (2014) trazem que a imagem física desses usuários, em decorrência do uso da droga, contribui para a formação da identidade desses sujeitos que passam a ser vistos como pertencentes de um grupo ou categoria no meio social.

\section{Satisfação com atendimento}

O acolhimento para os participantes avaliados no estudo é representado de maneira importante, que reflete satisfação no momento de troca, experiências e convívio com os profissionais como retratada nas seguintes falas:

'(...) Eu vou falar que eu tenho 07 anos aqui né, sou bem atendido (...). Esse tempo que tenho aqui só tenho a acrescentar em minha vida.

'Num tenho o que falar não... O pessoal aqui, o tratamento daqui é bom, é ótimo. Sou bem tratado",

Schneider (2009) apreende por meio da percepção quanto a satisfação dos usuários que o atendimento do CAPS é resolutivo, uma vez que é ressaltada a mudança no padrão de vida como aspecto positivo ao adentrar no serviço. O estudo de Lima (2015) reforça a questão da satisfação dos usuários ao serviço no que diz respeito a representatividade do ambiente no qual se encontra 
o usuário, bem como, a atuação dos profissionais, permitindo este local ser propulsor de possibilidades para os indivíduos que enfrentam as dificuldades causadas pela dependência química.

\section{Melhoria no atendimento}

A satisfação é alcançada quando são sanadas as necessidades dos usuários, sendo claro nas falas:

'Rapaz, ta bom. Não tem nada pra melhorar não.',

'Não, ta tranquilo mesmo.',

Resultados semelhantes são encontrados no estudo de Cardoso (2016) que mostra a satisfação dos usuários do CAPS com o atendimento, em que referiram um bom acolhimento, ambiente confortável, comodidade, sobretudo, quando comparado a outros serviços como os hospitais psiquiátricos em virtude das contenções físicas e intervenções medicamentosas que ocasionou sentimentos e sensações ruins aos usuários. Neste sentido de sentimentos atribuídos ao serviço, Lima (2015) e Botelho (2015) percebem o CAPS como um ambiente que proporciona interação, expressão de emoções e a sociabilidade dos usuários com os profissionais e familiares.

Assim como a satisfação, também foi reiterado a insatisfação quanto à falta de medicação, pouca diversidade de oficinas e falta da participação ativa no que diz respeito a opinar sobre as atividades no CAPS, conforme os relatos:

"Medicação chegar né (...)Medicação falta de vez em quando.",

'Eu achava que precisava assim ter mais uma terapia, assim, a mais nuns outros dias que atraísse mais a gente né. A gente assim, "fazesse" um debate e escolhesse assim, uma coisa pra fazer. Que todo mundo entrasse de acordo e pedisse, pra ver se conseguia vim praqui né. Assim, fora só essa terapia, tem outras coisas mais pra fazer a gente né, só não ter o grupo aqui, só segunda feira né."

Segundo Vasters (2011), o que caracteriza um serviço atrativo é a alternâncias das atividades que motiva os usuários a aderir à opção de estar no tratamento, no grupo específico, livres da exposição ao risco. Nasi e Schneider (2011) trazem que as oficinas terapêuticas contribuem para os usuários organizarem a sua vida diante da dependência causada por substâncias psicoativas. Moura (2011) reitera que essas oficinas têm um papel importante no enfrentamento do sofrimento psíquico para esses indivíduos, pois essas atividades possibilita a interação com outros sujeitos e a socialização de experiências, melhoras e dificuldades.

A participação da família é imprescindível no processo de tratamento, na fala do usuário é exposta a insatisfação nesta abordagem pela equipe do CAPS:

' O que ta precisando mais assim, é da parte dos profissionais pra família, chegar pra família, ligar pra família. Porque, a minha família ela não é preparada, né. Então o CAPS, ela pode ajudar minha família né, a poder me ajudar dentro de casa. Porque a gente ta sendo ajudado aqui. E lá dentro de casa?! Né? E lá dentro? Como é que fica? Porque não adianta a gente ser ajudado aqui e lá dentro, dentro da nossa casa, é, a nossa mãe não ter como nos ajudar né."

O familiar tem o importante papel no apoio do usuário em tratamento, principalmente na adesão, como reiteram em seus estudos Alvarez (2012), Jorge (2011) e Vasters; Pillon (2011) em que a responsabilização pelo paciente deve ser mútua, no sentido da atenção prestada pelo serviço e pela família, além da importância do profissional no apoio e acompanhamento terapêutico aos familiares.

\section{CONSIDERAÇÕES FINAIS}

O acolhimento realizado pelos trabalhadores do CAPS ad, para os usuários é percebido como importante propulsor para o tratamento, sendo atribuído a desde o primeiro contato com a instituição, a quem o acolheu, bem como, aos demais profissionais da instituição.

Além da satisfação com o atendimento, também foi encontrado a insatisfação quanto à distribuição da medicação, assim como a falta de variedades das oficinas terapêuticas, que caracteriza o serviço mais atrativo possibilitando maior adesão ao tratamento. Também, foi 
referida a fragilidade na comunicação dos profissionais do CAPS ad com os familiares, sendo indispensável o acompanhamento dessa família evitando a vulnerabilidade e incapacidade em lidar com as dificuldades causadas pelo uso de substâncias psicoativas, no âmbito familiar.

Nessa perspectiva, o CAPS deve contemplar as necessidades tanto dos usuários quanto dos familiares, sendo imprescindível o fortalecimento de vínculo e o resgate da autonomia do sujeito.

\section{REFERÊNCIAS}

ALVAREZ, S.Q. et al . Grupo de apoio suporte como estratégia de cuidado: importância para familiares de usuários de drogas. Rev Gaúcha Enferm, 33(2):102-108. Porto Alegre, 2012.

BARD, N.D. et al. Estigma e preconceito: vivência dos usuários de crack. Rev. Latino-Am. Enfermagem. 24:e 2680. Porto Alegre, RS. 2016.

BAUER, M. W; GASKELL, G. Pesquisa Qualitativa com Texto, Imagem e Som: um manual prático. Editora Vozes, Petrópolis, RJ. 2002.

BOTELHO, J.V; LIMA, M.V. Percepção das emoções dos usuários do caps ii: um relato de experiência. Revista de Psicologia, v. 27, n. 2, p. 160-164, Maio-Ago. 2015.

BRASIL. Ministério da Saúde. Resolução no 466 de 12 de dezembro de 2012 do Conselho

Nacional de Saúde. Brasília, DF: Ministério da Saúde, 2012.

BRASIL. Ministério da Saúde. Secretaria de Atenção à Saúde. Departamento de Ações

Programáticas Estratégicas. Saúde mental no SUS: os centros de atenção psicossocial.

Brasília, 2004.

BRASIL. Ministério da Saúde. Secretaria de Atenção à Saúde. Departamento de Atenção

Especializada e Temática. Centros de Atenção Psicossocial e Unidades de Acolhimento como lugares da atenção psicossocial nos territórios: orientações para elaboração de projetos de construção, reforma e ampliação de CAPS e de UA. Brasília, 2015.

CARDOSO, M.R.O. et al. Práticas de cuidado em saúde mental na voz dos usuários de um Centro de Atenção Psicossocial do estado do Pará. Saúde Debate, Rio de Janeiro, RJ v. 40, n. 109, p. 86-99, Abr-Jun, 2016.

GATTI, B. A. Grupo focal nas pesquisas em ciências sociais e humanas. Brasília: Liber Livro,2005.

GIL, A. C. Como elaborar projetos de pesquisa. 5 ed. São Paulo: Atlas, 2010. 184 p.

JORGE, M.S.B et al. Promoção da Saúde Mental- Tecnologia do cuidado: vínculo, acolhimento, co-responsabilização e autonomia. Ciência \& Saúde Coletiva. Fortaleza, CE. 2011.

LIMA, M.Z. et al.Percepção do cuidado em saúde no CAPS Ad: uma visão do paciente. Saúde (Santa Maria), Vol. 41, n. 1. Fortaleza, CE. Jan, 2015.

MOURA FG, SANTOS JE. O cuidado aos usuários de um centro de atenção psicossocial álcool e drogas: Uma visão do sujeito coletivo. SMAD, Rev. Eletrônica Saúde Mental Álcool Drog. (Ed. port.) Salvador-ba. Set.-dez. 2011.

NASI, C ; SCHNEIDER, J.F.O Centro de Atenção Psicossocial no cotidiano dos seus usuários.

Rev Esc Enferm USP. 45(5): 1157-63. Rio Grande do Sul, 2011.

ROMANINI. M, ROSO.A. Midiatização do crack e estigmatização: corpos habitados por histórias e cicatrizes. Interface (Botucatu). Vol.18 no.49 Botucatu, 2014.

SCHNEIDER, J. F. et al. Avaliação de um Centro de Atenção Psicossocial Brasileiro. Ciencia y EnfermerIa XV (3): 91-100, 2009.

TANAKA, O.Y. et al. Ações de saúde na atenção básica: caminho para ampliação da integralidade da atenção. Ciênc. saúde coletiva vol.14 no. 2 Rio de Janeiro/Mar. 2009. TRIVINÕS, A. N. S. Introdução à pesquisa em ciências sociais: a pesquisa qualitativa em educação: o positivismo, a fenomenologia, o marxismo. São Paulo: Atlas, 2008. 175 p. VASTERS GP, PILLON SC. O uso de drogas por adolescentes e suas percepções sobre adesão e abandono de tratamento especializado. Rev. Latino-Am. Enfermagem. São Paulo, Mar-Abr, 2011. 